\section{AUthors}

C.F. Redinger ${ }^{\mathrm{a}, \mathrm{b}}$

S.P. Levine ${ }^{\mathrm{b}}$

M.J. Blotzer

M.P. Majewski ${ }^{\mathrm{d}, \mathrm{e}}$

aRedinger and Associates, Inc., 1537 Fourth St., \#248, San

Rafael, CA 94901; e-mail:

cfredinger@attbi.com;

'University of Michigan-

Michigan State University WHO

Collaborating Center for

Occupational Health, 1420

Washington Heights, Ann Arbor,

MI 48109-2029;

'NASA John H. Glenn Research

Center, Mail Stop 6-4, 21000

Brookpark Road, Cleveland, $\mathrm{OH}$ 44135;

¿Syva Corp., Cupertino, CA;

'Formerly with Raychem Corp.,

Menlo Park, CA 95014
This research was made possible from the Education Resource Center support provided to the University of Michigan by the National Institute of Occupational Safety and Health, as well as funding received from the Kemper Foundation. Travel support was provided by Baxter Healthcare and NASA.

\title{
Evaluation of an Occupational Health and Safety Management System Performance Measurement Tool-IIl: Measurement of Initiation Elements
}

With the proliferation of occupational health and safety management systems (OHSMS) in the 1990s, an assessment instrument was developed at the University of Michigan to measure a wide range of OHSMSs. Due to the range of systems it was designed to measure, the instrument is referred to as a universal assessment instrument (UAI). Initial evaluation of the instrument's first four sections is reported here. This study shows that the UAl's initiation measurement criteria and measurement scales could make distinctions between the OHS management systems at three test sites. This was particularly evident in the case in an organization in which a standards-based OHSMS was not implemented. In this case the UAl's two measurement scales could distinguish between areas that were being developed (development scale) and areas that were in conformance with the measurement criteria (conformance scale). The score totals were consistent with the qualitative assessment using case study methods during field pilot testing; with the exception of Section 2.0, Employee Participation, in which scoring at one test site was not consistent with case study findings. It is suggested that the variables/measures presented in the UAl's OHSMS initiation organizing category may contain performance measures that may serve as key leading indicators of overall OHS performance.

Keywords: occupational health and safety management system, universal assessment instrument

$\longrightarrow$ ccupational health and safety (OHS) performance measurement continues to be an area of interest and importance to OHS professionals and their organizations. With the proliferation of OHS management systems (OHSMS) in the late 1990s, and the consequent need to understand the effectiveness of these models and systems, an assessment instrument was developed at the University of Michigan to measure a wide range of OHSMSs. Due to the range of management systems that the instrument covers, it is referred to as a universal assessment instrument (UAI). The UAI was developed to assist OHS professionals and their organizations in making determinations of OHS effectiveness, to measure OHSMS effectiveness, and in identifying OHS performance variables and measurements that are unique to the organization.

This article presents the findings from pilot tests of the UAI organizing category titled OHSMS Initiation, which contains four UAI sections: (1) Management Commitment and Resources (Sec. 1.0); (2) Regulatory Compliance and System Conformance (Sec. 1.1); (3) Accountability, Responsibility, and Authority (Sec. 1.2); and (4) Employee Participation (Sec. 2.0). 
TABLE I. UAl Section 1.0, Management Commitment and Resources, Input Clauses

\begin{tabular}{lccc}
\hline Input Model & $\begin{array}{c}\text { No. } \\
\text { Input } \\
\text { Clauses }\end{array}$ & $\begin{array}{c}\text { No. Cross } \\
\text { Reference } \\
\text { Clauses }\end{array}$ & $\begin{array}{c}\text { Total } \\
\text { Clauses }\end{array}$ \\
\hline VPP & 7 & 3 & 10 \\
BS 8800 & 6 & 7 & 13 \\
AlHA OHSMS & 6 & 4 & 10 \\
ISO 14001 & 6 & 3 & 9 \\
\hline
\end{tabular}

\section{OHSMS INITIATION}

0 HSMS Initiation refers to the act of defining the necessary elements and conditions essential to OHSMS formulation, implementation, and evaluation. These necessary elements include strong management commitment, allocation of sufficient resources, and robust employee participation. This UAI organizing category contains four UAI sections. Collectively these sections contain 17 OHSMS principles and 75 measurement criteria. From a systems perspective, ${ }^{(1,2)}$ these four sections are identified as the necessary inputs for an effective OHSMS.

\section{Management Commitment and Resources}

UAI Section 1.0 addresses management commitment and resource-related issues. Management commitment to OHS may be operationally defined in a number of ways. Allocation of sufficient resources for the proper functioning of an OHS program or management system has been identified in the input models as a key variable for measuring management commitment. Other variables, some of which are found in this section's OHSMS principles, are the establishment of organizational structures whereby managers and employees are supported in their OHS duties and the designation of a management representative who is responsible for overseeing the proper functioning of the OHSMS.

The importance of strong management commitment is reflected in the Occupational Safety and Health Administration's (OSHA) Voluntary Protection Programs (VPP); the British Standards Institute's (BSI) BS 8800; the American Industrial Hygiene Association's (AIHA) OHSMS; and the International Organization for Standardization's (ISO) 14001 (Table I). In fact, some OHS professionals assert that management commitment is the sine qua non of an OHSMS. The same may be said about employee participation (Section 2.0). Therefore, these two input variables must be present for the development of a robust OHSMS.

Based on the intradependent nature of the input models, many clauses address more than one OHSMS variable. In these cases the clauses were cross-referenced to other UAI sections. For example, as reflected in Table I, the VPP has seven clauses that directly relate to UAI Section 1.0. Three additional clauses also relate to this section, but are primary to other UAI sections. Therefore, there is a total of 10 clauses in the VPP that relate to UAI Section 1.0 and thus must be considered when using the UAI to make VPP-related determinations of effectiveness. These 10 clauses, as well as the 24 clauses from the other input models, influenced the development of this section's OHSMS principles and measurement criteria.

This UAI section contains five OHSMS principles:

COMMIT01. Senior management shall demonstrate their commitment to eliminating occupational injury and illness by fulfilling the OHSMS principles contained herein.
TABLE II. UAl Section 1.1, Regulatory Compliance and System Conformance, Input Clauses

\begin{tabular}{lccc}
\hline Input Model & $\begin{array}{c}\text { Number } \\
\text { of } \\
\text { Input } \\
\text { Clauses }\end{array}$ & $\begin{array}{c}\text { Number of } \\
\text { Cross } \\
\text { Reference } \\
\text { Clauses }\end{array}$ & $\begin{array}{c}\text { Total } \\
\text { Clauses }\end{array}$ \\
\hline VPP & 0 & 0 & 0 \\
BS 8800 & 3 & 3 & 6 \\
AlHA OHSMS & 6 & 2 & 8 \\
ISO 14001 & 3 & 1 & 4 \\
\hline
\end{tabular}

COMMIT02. Senior management shall demonstrate their commitment to eliminating occupational injury and illness through the allocation of sufficient resources so that the OHSMS can function as planned and OHS goals and objectives can be met.

COMMIT03. Senior management shall demonstrate their commitment to eliminating occupational injury and illness through the establishment of organizational structures that support the OHS policy, goals, and objectives.

COMMIT04. The organization shall designate a management representative who will oversee the OHSMS and ensure its proper functioning.

COMMIT05. Senior management shall encourage and support employees in fulfilling OHS goals and objectives.

\section{Regulatory Compliance and System Conformance}

UAI Section 1.1 addresses regulatory compliance and system conformance issues. Many governmental regulations and nongovernmental standards impose requirements on OHS management and therefore can affect the way an OHSMS is formulated, implemented, and evaluated. Organizations need to understand the governmental regulations and nongovernmental standards that impact them. Striving for compliance or conformance with regulations and standards should be a top priority of the organization.

It is not the intent in this section's OHSMS principles to identify for the organization the applicable regulations and standards. Rather, the purpose is to ensure that the organization has a system to identify, document, and implement applicable governmental and nongovernmental requirements.

Table II shows the number of input model clauses associated with this section's principles and measurement criteria.

This UAI section contains two OHSMS principles:

REG01. The organization shall demonstrate a commitment to be in compliance with governmental OHS regulations and in conformance with applicable nongovernmental standards and corporate policies.

REG02. The organization shall have access to current and applicable OHS governmental regulations, nongovernmental standards, and corporate policies.

\section{Accountability, Responsibility, and Authority}

UAI Section 1.2 addresses the manner in which the organization defines the roles of personnel who are involved in OHS management, and the employees, supervisors, and managers who are affected by it. Crucial to role definition is the manner in which OHS and OHSMS accountability, responsibility, and authority are defined, supported, and enforced by senior management.

Potential discrimination against personnel who have OHSMS management responsibilities is prevented. Repeated and/or willful violations of occupational health and safety procedures should be subject to reprimand. 
TABLE III. UAI Section 1.2, Accountability, Responsibility, and Authority; Input Clauses

\begin{tabular}{lccc}
\hline Input Model & $\begin{array}{c}\text { No. } \\
\text { Input } \\
\text { Clauses }\end{array}$ & $\begin{array}{c}\text { No. Cross } \\
\text { Reference } \\
\text { Clauses }\end{array}$ & $\begin{array}{c}\text { Total } \\
\text { Clauses }\end{array}$ \\
\hline VPP & 5 & 5 & 10 \\
BS 8800 & 5 & 6 & 11 \\
AIHA OHSMS & 1 & 5 & 6 \\
ISO 14001 & 4 & 5 & 9 \\
\hline
\end{tabular}

Table III shows the number of input model clauses associated with this section's principles and measurement criteria.

This UAI section contains four OHSMS principles:

ACCOUNT01. The organization shall have defined roles for personnel responsible for OHSMS formulation, implementation, and evaluation-and for personnel accountable for OHSMS performance.

ACCOUNT02. Senior management shall ensure that appropriate authority has been delegated to personnel who have OHSMS responsibilities and are accountable for OHSMS performance.

ACCOUNT03. The organization shall define roles and responsibilities that line personnel, technicians, support staff, and so forth have in the OHSMS.

ACCOUNT04. The organization shall establish a mechanism to document and reprimand personnel (e.g., managers, supervisors, and employees) who willfully and/or repeatedly disregard OHS-related policies and procedures.

\section{Employee Participation}

UAI Section 2.0 addresses issues related to employee participation in OHS management, which in OHS management may be operationally defined in a number of ways. The key issue is that employees have input into OHS considerations, and that the input is meaningful, valued, and can affect policies and practices. Other important variables, some of which are found in this section's OHSMS principles, include employee participation in OHSMS formulation, implementation, and evaluation activities.

Many OHS professionals have identified employee participation in OHS management as the variable most essential to successful OHS management and illness/injury reduction. ${ }^{(3)}$ Employee participation and management commitment (Section 1.0) are identified as two input variables that must be present in a robust and effective OHSMS.

Table IV shows the number of input model clauses associated with this section's principles and measurement criteria.

This UAI section contains six OHSMS principles:

EMPLOY01. The organization shall have a system to ensure that there is employee participation in OHSMS formulation, implementation, and evaluation activities.

TABLE IV. UAI Section 2.0, Employee Participation, Input Clauses

\begin{tabular}{lccc}
\hline Input Model & $\begin{array}{c}\text { No. } \\
\text { Input } \\
\text { Clauses }\end{array}$ & $\begin{array}{c}\text { No. Cross } \\
\text { Reference } \\
\text { Clauses }\end{array}$ & $\begin{array}{c}\text { Total } \\
\text { Clauses }\end{array}$ \\
\hline VPP & 7 & 2 & 9 \\
BS 8800 & 2 & 1 & 3 \\
AlHA OHSMS & 2 & 4 & 6 \\
ISO 14001 & 0 & 1 & 1 \\
\hline
\end{tabular}

EMPLOY02. Employee concerns and input on OHS issues shall be encouraged and valued.

EMPLOY03. Employees shall have easy access to OHSMS documents and records.

EMPLOY04. In organizations where collective bargaining units are present, their input and participation in the OHSMS shall be encouraged and valued.

EMPLOY05. Except where prohibited by law or collective bargaining agreements, the organization shall facilitate the formation of a health and safety committee comprised of employees from different levels in the organization.

EMPLOY06. The organization shall ensure that the health and safety committee is a viable route for the expression of employee concerns and input into OHS issues.

\section{METHODS}

$M$ ethods, site selection criteria, and characteristics are presented in detail in the preceding articles of this series. ${ }^{(4,5)}$ The goals of the pilot test were to:

(1) evaluate the ability of the UAI's OHSMS principles and measurement criteria to address and measure OHSMSs that were implemented at the test sites;

(2) evaluate and further develop the UAI's OHSMS scoring system;

(3) observe how the test sites defined and managed OHS;

(4) use these key findings to begin the construction of a comprehensive OHSMS theory; and

(5) make modifications to the UAI as necessary based on pilot test findings.

\section{RESULTS AND ANALYSIS}

\subsection{Management Commitment and Resources (COMMIT)}

Each test site had a written OHSMS policy statement either in the form of an OHS policy statement or an environmental health and safety (EHS) policy statement. The policy statements for Organizations A and B each clearly identified the organization's management and allocation of resources for the OHSMS. This is consistent with the fact that these two sites were both ISO 14001 registered. Organization C's OHSMS policy statement was not explicit in this area. Finally, Organization A's and B's posted policy statements were signed by their respective CEOs; Organization C's was not signed. For Organization C, even though posted copies were not signed, the master file copy was.

Organization A's corporate environmental, occupational health, and safety policy stated that "compliance with this policy requires top management leadership, and recognition by all managers that outstanding EHS performance is one of our corporate priorities."'(6)

In the case of Organization B, its Environmental Health and Safety Policy statement identifies eight operating principles that are essential to its EHS program. Principal 3 relating to resources states: "We will ensure adequate resources to provide coordinated and effective environmental, health, and safety programs through awareness, training and continuous evaluation.”(6)

\section{UAI Analysis-Section 1.0}

This UAI section contains five OHSMS principles and 22 measurement criteria (Table V). It was found that all of the principles were relevant to the three test sites. Each test site had operationally 
TABLE V. UAI Section 1.0, Scoring Results

\begin{tabular}{lccc}
\hline & Org. A & Org. B & Org. C \\
\hline COMMIT01 & 2 & 3 & 1 \\
COMMIT02 & 2 & 3 & $\mathrm{~A}$ \\
COMMIT03 & 2 & 2 & $\mathrm{~A}$ \\
COMMIT04 & 1 & 2 & $\mathrm{~A}$ \\
COMMIT05 & 1 & 3 & 1 \\
Total & $8(53 \%)$ & $13(87 \%)$ & $2(13 \%)$ \\
\hline
\end{tabular}

defined its OHSMS principles in a similar manner, with slight variations. Sixty-eight percent $(15 / 22)$ of the measurement criteria were relevant to all the test sites. Several exceptions were noted when criteria did not appear relevant. For example, UAI COMMIT02.CRITERION.05 states: "There is a system in place to evaluate the adequacy of the disbursed resources." Such a system was not formally defined or in place at any of the test sites. This issue was addressed informally in some fashion at all test sites. Based on this, this criterion along with the other seven that were not directly relevant to the test sites will be examined further in future UAI evaluation efforts.

As described in the previous paper, ${ }^{(4)}$ two measurement scales were developed to measure the UAI's principles. The total available points for this UAI section was 15 .

On the nonnumeric evaluation scale, Organization C obtained 3 A's, 0 B's, and 0 C's for this section. This indicates that many, but not all, measurement criteria were in conformance in the three principles that received the nonnumeric ratings.

\section{1, Regulatory Compliance (REG)}

Organization A's and Organization B's policy statements were explicit in their commitment to regulatory compliance. ${ }^{(6)}$ Organization C's policy statement, although it did discuss the importance of EHS regulations to its operations, and the changing nature of these regulations, it did not include a statement regarding the organization's commitment to such compliance. ${ }^{(6)}$ Organization A's policy stated: Compliance with Regulations: We will develop, manufacture, and distribute our products so as to consistently comply with applicable EHS regulations. We will support the development of scientifically based and risk-management-based EHS laws and regulations.

Organization B's policy states: "We will commit to meeting or exceeding governmental regulations and complying with internal environmental, health, and safety management standards."(6)

\section{UAI Analysis-Section 1.1}

This UAI section contains two OHSMS principles and 10 measurement criteria (Table VI). It was found that principle REG01 and its measurement criteria did not perform well in the pilot tests. The fact that this principle addresses two issues, regulatory compliance and system conformance, proved to be problematic. It was found that two principles are needed here to better distinguish between these two issues. Nevertheless, it was found that all (10/ 10) of the measurement criteria were relevant to the test sites.

\section{TABLE VI. UAI Section 1.1, Scoring Results}

\begin{tabular}{lccc}
\hline & Org. A & Org. B & Org. C \\
\hline REG01 & 1 & 2 & 1 \\
REG02 & 2 & 3 & 2 \\
Total & $3(50 \%)$ & $5(83 \%)$ & $3(50 \%)$ \\
\hline
\end{tabular}

TABLE VII. UAI Section 1.2, Scoring Results

\begin{tabular}{lccc}
\hline & Org. A & Org. B & Org. C \\
\hline ACCOUNT01 & 1 & 2 & 1 \\
ACCOUNT02 & 2 & 2 & $\mathrm{~A}$ \\
ACCOUNT03 & 1 & 3 & 1 \\
ACCOUNT04 & $\mathrm{A}$ & 1 & $\mathrm{~A}$ \\
Total & $4(33 \%)$ & $8(67 \%)$ & $2(17 \%)$ \\
\hline
\end{tabular}

Based on the pilot test findings, this OHSMS principle will be modified by creating two principles to address governmental and nongovernmental compliance issues independently.

For evaluation of this section's OHSMS principles, the total of available points was 6 .

\section{2, Accountability, Responsibility, and Authority (ACCOUNT)}

Organization A's policy statement addressed the need to establish accountability and responsibility in its EMS/OHSMS. Organization B's policy statement was not explicit in this area. However, the organization's commitment can be inferred from its policy statement. Organization C's policy statement, although it did discuss the importance of such role definition, did not include a statement regarding commitment in this area. Several EHS/OHSMS roles are defined, however. ${ }^{(6)}$

Beyond the management level, examples were found at all test sites in specific procedures when the accountability and responsibility of line supervisors and personnel were addressed.

\section{UAI Analysis-Section 1.2}

This UAI section contains four OHSMS principles and 16 measurement criteria (Table VII). It was found that the principles were relevant to all three test sites. All test sites had operationally defined the principles in a similar manner, with slight variations. Verification of the principles was difficult because the test sites defined the OHS variables and measurements associated with this UAI section throughout various OHS and non-OHS policies and procedures.

Sixty-nine percent $(11 / 16)$ of the measurement criteria were relevant to the test sites. Several exceptions were noted for which criteria were not relevant. For example, ACCOUNT01. CRITERION.04 states: "The procedures and job/position descriptions have been implemented." It was found that job/position descriptions were written at all test sites. The statement "have been implemented" does not appear to be relevant. Based on this, this criterion, along with the other four which were not directly relevant to the test sites, will be examined in future evaluation studies.

The total available points for this UAI section was 12 .

On the nonnumeric evaluation scale, Organizations A and C received 1 and 2 A's, respectively, for this section. This indicates that many measurement criteria, but not all, were in conformance in these measurement criteria.

\section{0, Employee Participation (EMPLOY)}

\section{Definition}

Each organization's policy statement addressed the role of employees. Organization A's policy stated: “Active Involvement by All Employees: We will properly train our employees on relevant EHS topics and hold them responsible and accountable for complying with our policies, procedures, and standards. Working safely and in an environmentally responsible manner will be conditions of employment."'(6) 
TABLE VIII. UAI Section 2.0, Scoring Results

\begin{tabular}{lccc}
\hline & Org. A & Org. B & Org. C \\
\hline EMPLOY01 & $\mathrm{A}$ & $\mathrm{A}$ & $\mathrm{A}$ \\
EMPLOY02 & 1 & 1 & 2 \\
EMPLOY03 & 1 & 2 & 2 \\
EMPLOY04 & $\mathrm{N} / \mathrm{A}$ & $\mathrm{N} / \mathrm{A}$ & 2 \\
EMPLOY05 & 1 & 1 & 1 \\
EMPLOY06 & $\mathrm{A}$ & 1 & 2 \\
Total & $3(20 \%)$ & $5(33 \%)$ & $9(50 \%)$ \\
\hline
\end{tabular}

In relation to employee participation, Organization B's policy stated: "We will ensure that employees will have the awareness, skills and knowledge to carry out this policy. We will provide workplaces free from recognized hazards and promote healthy lifestyles."(6) Organization C's policy stated: [Organization C] employees must be aware of the current policies and procedures, the impact these policies and procedures have on [Organization C] activities and operations, the individual responsibility each employee has to comply with these policies and procedures, and the personal liability one accepts when not complying with these policies and procedures. ${ }^{(6)}$

\section{UAI Analysis-Section 2.0}

This UAI section contains six OHSMS principles and 26 measurement criteria (Table VIII. It was found that the principles were relevant to all three test sites, with the exception of EMPLOY04, which was not relevant to Organizations A or B, because they do not have collective bargaining units. With the remaining principles all test sites had operationally defined the principles in a similar manner, with slight variations.

Of the input models, OSHA's VPP is the strongest in the area of employee participation. In this area Organization $\mathrm{C}$ could pass an ISO 9001 (e.g., AIHA OHSMS) or 14001-based OHSMS registration audit. However, based on the employee-management dynamics present at the site, it is doubtful that an OSHA VPP onsite review team would grant Star status. This difference between the various input models in the area of employee participation is potentially significant.

Not including the six measurement criteria contained in EMPLOY04, 85\% (17/20) of the measurement criteria were relevant to all the test sites. Several exceptions were noted where criterion did not appear relevant. For example, EMPLOY02.CRITERION.05 states: "Actions taken in response to employee concerns and input are communicated back to the employee." Formal feedback systems such as this were not observed at the test sites. Informal systems were present, but they varied between the sites. Based on this, this criterion, along with the other two that were not directly relevant to the test sites, will be examined further in future studies.

The totals of available points for this UAI section were 15 for Organizations A and B, and 18 for Organization C.

On the nonnumeric evaluation scale, all three organizations received A's for EMPLOY01. EMPLOY04 could not be applied to Organizations A and B because these sites did not have organized collective bargaining units. Finally, Organization A received an "A" for EMPLOY06.

\section{DISCUSSION AND CONCLUSIONS}

$T_{\mathrm{i}}^{\mathrm{h}}$ he results of the UAI pilot tests have shown that the UAI initiation measurement criteria and measurement scales are able to make distinctions among the three OHSMSs evaluated. This
TABLE IX. Scoring Results Summary, OHSMS Initiation

\begin{tabular}{lrrr}
\hline & \multicolumn{1}{c}{ Org. A } & \multicolumn{1}{c}{ Org. B } & \multicolumn{1}{c}{ Org. C } \\
\hline 1.0 COMMIT & $8(53 \%)$ & $13(87 \%)$ & $2(13 \%)$ \\
1.1 REG & $3(50 \%)$ & $5(83 \%)$ & $3(50 \%)$ \\
1.2 ACCOUNT & $4(33 \%)$ & $8(67 \%)$ & $2(17 \%)$ \\
2.0 EMPLOY & $3(20 \%)$ & $5(33 \%)$ & $9(50 \%)$ \\
Total & $18(38 \%)$ & $31(65 \%)$ & $16(31 \%)$ \\
\hline
\end{tabular}

was particularly evident in the case of Organization C, where a standards-based OHSMS was not implemented. In this case the UAI's two measurement scales could distinguish between areas that were being developed (development scale) and areas that were in conformance with the measurement criteria (conformance scale).

A total of 48 points was available to describe initiation OHSMS principles for Organization A and B, and 51 for Organization C. These totals are presented in Table IX.

The score totals are consistent with the qualitative assessment performed using case study methods during field pilot testing, with the exception of Section 2.0, Employee Participation. In the case of Organization $\mathrm{C}$, the score was higher than would be suggested by case study findings, because the measurement criteria did not appear to adequately measure breakdowns in the established employee participation structures. In the case of Organization B the Section 2.0 score is lower than those obtained in the other three UAI sections. This is because the employee participation structures were relatively new and not yet sustained.

Professor Kim Cameron, who is an expert in organizational measurement, has identified the issues that make organizational effectiveness determinations and measurement difficult to conduct. In relation to OHS management and effectiveness measurement, the UAI directly addresses the challenges presented by Cameron. ${ }^{(7-8)}$ The UAI offers a way to move from a conceptual level to an operational level at which effectiveness can be measured. Through the measurement criteria a measurement standard is presented. Because the OHSMS principles (conceptual level) are based on four sound OHSMS models, the UAI conceptual foundation is sound.

As indicated in this article, OHS and OHSMS effectiveness determinations are value-based and will change from organization to organization. Obviously, operational effectiveness is clearly measured as the extent to which worker health and safety is protected. Critics of OHSMSs (especially models that are based purely on ISO 9000) argue that without some baseline criteria, OHSMSs may not protect worker health.

The approach presented in the UAI directly addresses this concern. Much as QS-9000(9) provides criteria for the automobile industry in relation to the generic ISO 9000 standard, ${ }^{(10,11)}$ the UAI presents measurement criteria (operational definitions) that can be used to ensure that OHSMS principles (conceptual level) adequately address the issues that are known to affect worker health and safety (operational level).

More work is needed to identify the leading OHS indicators that directly affect occupational illness, injury, and fatality incidence rates. It is suggested that the variables/measures presented in the UAI's OHSMS initiation organizing category may contain some of these key leading indicators.

\section{REFERENCES}

1. von Bertalanffy, L.: The Theory of Open Systems in Physics and Biology. Science 111:23-29 (1950). 
2. Katz, D., and R. Kahn: The Social Psychology of Organizations. New York: John Wiley \& Sons, 1966.

3. "Safety and Health Program Management Guidelines." Federal Register (26 January 1989).

4. Redinger, C.F., and S.P. Levine: Evaluation of an occupational health and safety management system performance measurement tool-II: Scoring methods and field study sites. Am. Ind. Hyg. Assoc. J. 62:34-40 (2001).

5. Redinger, C.F., and S.P. Levine: Development and evaluation of the Michigan Occupational Health and Safety Management System Assessment Instrument: A universal OHSMS performance measurement tool. Am. Ind. Hyg. Assoc. J. 59:572-581 (1998).

6. Redinger, C.F.: "Occupational Health and Safety Management System Conformity Assessment: Development and Evaluation of a Universal Assessment Instrument." PhD diss., University of Michigan, Ann Arbor, 1998.
7. Cameron, K.S.: "Effectiveness as paradox: Consensus and conflict in conceptualizations of organizational effectiveness." Manage. Sci. 23: 539-553 (1986).

8. Cameron, K.S.: Organizational effectiveness. In Nigel Nicholson, editor, Encyclopedic Dictionary of Organizational Behavior. Oxford: Blackwell Publishers, 1995.

9. Automotive Industry Action Group: Quality System Requirements, QS 9000, 2nd ed. Detroit, Mich.: Automotive Industry Action Group, 1995.

10. American Industrial Hygiene Association (AIHA): Occupational Health and Safety Management System: An AIHA Guidance Document. Fairfax, Va.: AIHA, 1996.

11. International Organization for Standardization (ISO): Quality Systems-Model for Quality Assurance in Design, Development, Production, Installation and Servicing [International Standard ISO 9001: 1994(E)]. Geneva, Switzerland: ISO, 1995. 